\title{
A construção de um mito: Antônio de Albuquerque e o levante emboaba*
}

\section{Adriana Romeiro ${ }^{\text {布 }}$}

Este artigo examina a construção da imagem de herói pacificador em torno de Antônio de Albuquerque, governador da capitania do Rio de Janeiro e depois da capitania de São Paulo e Minas do Ouro, considerado o responsável pela pacificação da Guerra dos Emboabas. Descrito por Cláudio Manuel da Costa como um herói dotado das virtudes da coragem e prudência, tal imagem se deslocaria depois para os estudos históricos, conformando as narrativas sobre a Guerra dos Emboabas, em particular, e a administração de Albuquerque, em geral.

Palavras-chave: Guerra dos Emboabas, Antônio de Albuquerque, Cláudio Manuel da Costa.

The construction of a myth: Antônio de Albuquerque and the Emboaba rebellion.

This article examines the construction of the image of peacemaker hero Antônio de Albuquerque, governor of the captaincy of Rio de Janeiro and then the captaincy of São Paulo and Minas do Ouro, considered responsible for the pacification of the War of Emboabas. Described by Cláudio Manuel da Costa as a hero endowed with virtues like courage and wisdom, such image would then spread to historical studies,

${ }^{\otimes}$ Artigo recebido em julho de 2008 e aprovado para publicação em agosto de 2009. Este artigo originou-se de uma pesquisa financiada pelo $\mathrm{CNPq}$, por meio da Bolsa de Produtividade em Pesquisa.

凶 Doutora em História pela Universidade Estadual de Campinas. Pós-doutorado na Universidade de São Paulo. Atualmente é professor adjunto da Universidade Federal de Minas Gerais. E-mail: adriana.romeiro@uol.com.br. 
influencing the narratives on the War of Emboabas in particular, and the Albuquerque administration in general.

Keywords: War of Emboabas, Antônio de Albuquerque, Cláudio Manuel da Costa.

La construction d'un mythe : Antônio de Albuquerque et la rébellion Emboaba.

Cet article examine la construction d'une image de héros autour de Antônio de Albuquerque, gouverneur de la Capitainerie de Rio de Janeiro et plus tard, de la Capitainerie de São Paulo et Minas do Ouro, considéré le responsable de la pacification de la Guerre de Emboabas. Décrit par Cláudio Manuel da Costa comme un héros doté des vertus de courage et de sagesse, cette image s'est étendue plus tard aux études historiques, et ont influencé tout particulièrement les textes explicatifs sur la Guerre de Emboabas, et sur l'administration d'Albuquerque, en général.

Mots-cléfs: Guerre de Emboabas, Antônio de Albuquerque, Cláudio Manuel da Costa.

No poema "Vila Rica", Cláudio Manuel da Costa canta em versos a jornada de Antônio de Albuquerque em direção às Minas, tumultuadas pelo conflito armado entre paulistas e emboabas, que ali teve lugar em meados de 1709. À moda do herói medieval, o governador atravessa florestas e bosques densos e escuros, emoldurados pelo sobrenatural que se revela a cada passo, colocando o funcionário régio em contato com outra realidade, inquietante e por vezes assustadora. Tateando por esse universo ambíguo, ele se move determinado pelo firme propósito de apaziguar a região e estabelecer ali o poder da Coroa portuguesa. No "Fundamento Histórico", texto que subsidia o poema, o poeta assim descreve a chegada do herói à região mineradora: "prostraramse aos pés de Albuquerque os rebeldes, e desculparam como lhes foi possível os seus crimes: o Governador os recebeu afavelmente, não querendo usar do poder e das ordens de que vinha fortalecido; segurou a todos o perdão pela emenda que dessem a conhecer para o futuro; e não tardou a capacitar a Manuel Nunes Viana e Antônio Francisco que não convinha a assistência deles nas Minas Gerais, por sossegar de uma vez o tumulto dos povos”. Comparado a Cortés, Albuquerque teria, na pena do poeta, sido "o primeiro que susteve com desembaraço as rédeas do governo; que pisou as Minas com luzimento e 
firmeza do caráter, em que El-Rei o pusera; que promulgou as leis do Soberano, e fez respeitar neste Continente o seu nome". ${ }^{1}$

No "Prólogo", Cláudio adverte o leitor de que o poema é "uma memória por escrito das virtudes de um Herói que fora digno de melhor engenho para receber um louvor completo". ${ }^{2}$ Mas, afinal, onde reside mais precisamente o caráter heróico de Albuquerque? O poeta o responde de forma inequívoca: o "merecimento de um General que tão prudentemente pacificou um Povo rebelde, que segurou a Real Autoridade e que estabeleceu e firmou, entre as diferentes emulações de uns e outros Vassalos desunidos, os interesses que se deviam aos Soberanos Príncipes de Portugal". ${ }^{3}$ Pacificação dos revoltosos e implantação do poder metropolitano - eis as duas linhas de força em torno das quais se desenvolve o elogio a Albuquerque.

Estudos mais recentes têm observado, porém, que é preciso acautelarse ante o suposto caráter heróico de Albuquerque na poesia claudiana. Eliana Muzzi nota, por exemplo, que, no "Prólogo", o objeto do louvor desliza subrepticiamente para o elogio das riquezas das Minas, as quais "tem derramado por toda a Europa, e pelo muito que socorrem com a fadiga de seus habitantes ao comércio de todas as nações polidas". ${ }^{4}$ Para Hélio Lopes, o governador não passa de um herói de fachada, que só desempenha suas tarefas graças à intervenção favorável do maravilhoso, que é uma prerrogativa da terra. Segundo ele, "o poeta mineiro muito discretamente afasta o nome do herói do frontispício da obra e o relega a segundo plano". 5

Posicionando-se contrariamente à interpretação tradicional segundo a qual o poema nada mais faz do que exaltar a empresa colonizadora, configurada na instalação da máquina administrativa colonial nas Minas, Sérgio Alcides argumenta que tal perspectiva tende a superestimar um aspecto do problema, pois, segundo ele, "o poeta mineiro não se identifica com a colonização propriamente, e sim com a negociação que se empreende para viabilizá-la”. ${ }^{6}$ A observação deste autor joga luzes sobre um aspecto geralmente negligen-

\footnotetext{
${ }^{1}$ Cláudio Manuel da Costa, "Vila Rica". In: Domício Proença Filho (org.), A poesia dos inconfidentes: poesia completa de Cláudio Manuel da Costa, Tomás Antônio Gonzaga e Alvarenga Peixoto, Rio de Janeiro, Nova Aguilar, 1996, p. 372.

${ }^{2}$ Idem, p. 359.

${ }^{3}$ Idem, p. 359.

${ }^{4}$ Eliana Scotti Muzzi, "Epopéia e história”. In: Domício Proença Filho, op. cit., p. 352.

${ }^{5}$ Hélio Lopes, Introdução ao poema "Vila Rica", Muriaé, s/n, 1985, p. 45.

${ }^{6}$ Sérgio Alcides, Estes penhascos: Cláudio Manuel da Costa e a paisagem das Minas, 1753-1773, São Paulo, Hucitec, 2003, p. 229.
} 
ciado não só na obra claudiana, mas também nos estudos históricos sobre a Guerra dos Emboabas, articulando-se diretamente com o teor da empresa pacificadora levada a cabo por Albuquerque. Afinal, como se desenrola no poema a reconciliação entre paulistas e emboabas? Curiosamente, se o poema demora-se na jornada do governador, preparando o leitor para um evento futuro que, a todo momento, se projeta sobre os personagens como uma sombra perturbadora, o encontro com os revoltosos, porém, está desprovido de tensão ou conflito, configurando uma espécie de anticlímax que compromete o ritmo da obra. Daí a impropriedade do termo negociação para designar a natureza da pacificação encetada por Albuquerque, pois se o entendemos como um processo em que cada uma das partes envolvidas é obrigada a recuar de seus interesses, em favor de outrem, fica claro que no poema isso não ocorre. Aliás, a bravura do governador fica tanto mais desconcertante quanto mais serena é a sua jornada: apesar dos temores que o rondam e do espectro de D. Rodrigo de Castelo Branco a lembrá-lo da própria morte trágica, é como os sertões se abrissem, dóceis, à sua passagem. Quando, ao final, Albuquerque intima Manuel Nunes Viana a obedecê-lo, obrigando-o a se retirar para os sertões, o chefe emboaba simplesmente aquiesce, sem lhe opor qualquer resistência. A Cláudio, que não nutria simpatia pelos emboabas, identificando-os à anarquia e ao crime, certamente não agradaria a possibilidade de transação com tal categoria de homens.

A bem dizer, nada há, ao longo do poema, que aproxime a ação heróica do governador a uma conquista militar de caráter épico, e os rebeldes, colocados em plano secundário, limitam-se tão-somente a conspirar, em conciliábulos estéreis, sobre as possibilidades de impedir o seu avanço sobre as Minas. E o próprio Cláudio percebe aí uma qualidade excepcional do protagonista: menos do que uma investida militar, a sua estratégia consiste sobretudo em "mover por arte e por indústria os Povos". ${ }^{7}$ É, portanto, pela via da brandura, atributo de um homem letrado e culto, que ele tenta convencer a turba amotinada, ameaçando-a com o recurso à violência, apenas se não fosse obedecido.

Mas o propósito aqui não é tanto discutir o poema em si, quanto refletir sobre os desdobramentos que a saga heróica de Albuquerque, formulada primeiramente por Cláudio Manuel da Costa, teve nos estudos históricos sobre a Guerra dos Emboabas, constituindo uma matriz analítica que, atravessando

\footnotetext{
${ }^{7}$ Cláudio Manuel da Costa, Vila Rica, p. 422.
} 
os séculos, chegou até nós, vigorosa e influente, fixando uma certa concepção da história mineira do Setecentos.

Para se entender a construção a um só tempo histórica e poética do episódio, é necessário examinar as fontes que subsidiam o poema. No "Fundamento Histórico", o poeta cita particularmente o relato de autoria de Bento Fernandes Furtado, que lhe teria confiado, pouco antes de morrer, "alguns apontamentos", além do auxílio inestimável de Pedro Taques de Almeida, que o municiou com toda sorte de documentos, a exemplo de "ordens régias, cartas de governadores e atestações de prelados eclesiásticos, e manuscritos desde a era de $1682 " .{ }^{8}$ Os apontamentos a que se refere Cláudio constituem a narrativa intitulada "Notícias dos primeiros descobridores das primeiras minas de ouro pertencentes a estas Minas Gerais, pessoas mais assinaladas nestes empregos e dos mais memoráveis casos acontecidos desde os seus princípios", publicada recentemente na edição crítica do Códice Costa Matoso, organizada pela Fundação João Pinheiro. Surpreendentemente, nela a figura de Albuquerque está longe de alcançar a relevância que lhe atribui o poeta mineiro, e a sua atuação na pacificação do conflito entre paulistas e emboabas é descrita de forma sucinta e apressada, num tom muito diverso do épico claudiano. Na verdade, é na História da América Portuguesa, de Rocha Pita, que Albuquerque é primeiramente descrito como grande herói pacificador: partidário dos emboabas, aos quais atribuía o êxito de estabelecer a ordem em meio à tirania dos paulistas, Pita descreveu a passagem do governador pelas Minas como uma empresa destinada a "reduzir aquele grande número de súditos, que vagava sem firmeza, à vida urbana e política, erigindo as seis vilas cujos nomes deixamos já escritos". À exaltação da figura do governador pelos emboabas, que teriam mesmo rogado a sua intervenção em território mineiro, contrapõe-se a detração dos paulistas, descritos como os adversários acérrimos de Albuquerque, desrespeitosamente ameaçado e maltratado por eles no célebre encontro nas imediações da vila de Guaratinguetá. ${ }^{9}$ É interessante observar que, ao mesmo tempo em que o poema se impõe como contraponto crítico à obra de Rocha Pita, fartamente contestado pelo autor, ele não deixa de validar o seu elogio a Albuquerque, apresentando-o, inversamente, como simpático à causa paulista, num claro exercício de licença poética.

\footnotetext{
${ }^{8}$ Idem, p. 360.

${ }^{9}$ Sebastião da Rocha da Pita, História da América Portuguesa, Belo Horizonte/Itatiaia, São Paulo/Edusp, 1976, p. 246.
} 
O certo é que a versão heróica e épica de Cláudio Manuel da Costa dos eventos ligados à jornada e à atuação de Albuquerque na Guerra dos Emboabas - esboçada anteriormente por autores como Rocha Pita e Manuel da Fonseca - contaminaria grande parte das crônicas setecentistas sobre os albores da história mineira, constituindo uma matriz que, deslizando do campo da ficção, se instalaria definitivamente nos estudos históricos dos séculos seguintes. Para além das divisões ideológicas que marcaram tão fortemente tais obras, filiadas aos grupos envolvidos no conflito, a figura de Albuquerque - visto como partidário ora dos paulistas, ora dos emboabas - permaneceria como exemplo de funcionário justo e competente, o responsável pela introdução da ordem numa terra dominada pela barbárie. Mesmo um autor como Teixeira Coelho, que, ao contrário de Cláudio Manuel da Costa, refutava abertamente toda tentativa de exaltação dos descobridores da capitania, alegando que "nenhum interesse resulta ao Estado de semelhantes averiguações, que unicamente podem servir de glória aos descendentes dos mesmos descobridores", mesmo ele devotaria um verdadeiro culto ao governador. Crítico da simpatia de Cláudio aos paulistas, Teixeira Coelho, em sua Instrução para o governo da capitania de Minas Gerais, de 1780, assim resumiu a atuação do herói claudiano: "sossegou este Governador os povos, pacificou as desordens, deu forma ao governo e fez observar as leis do soberano". E associou, curiosamente, a falta de resistência - da qual resultou o êxito do governador - a uma natural obediência dos habitantes das Minas, uma vez que não se pode "imputar ao corpo daquela província a rebeldia de alguns indivíduos ínfimos da plebe”. Como Cláudio, Teixeira Coelho sobrepôs à imagem de pacificador a de herói civilizador, notando que "sem a menor oposição, reduziu este Governador, em menos de um ano, os habitantes de Minas a uma tranqüilidade geral e fez que uns povos dispersos, sem governo legítimo, se unissem nas vilas que criou, sujeitando a liberdade em que viviam para serem verdadeiramente livres e felizes debaixo da proteção das leis, que é o grande objeto delas". ${ }^{10}$

Num artigo sobre os primórdios da historiografia mineira, Maria Efigênia Lage de Resende chamou a atenção para os inúmeros paralelismos existentes entre o "Fundamento Histórico" de Cláudio Manuel da Costa e a obra de Teixeira Coelho, os quais a levaram a concluir que a fonte deste último residira nos escritos históricos do poeta mineiro. Na verdade, a influência tanto

${ }^{10}$ José João Teixeira Coelho, Instrução para o governo da capitania de Minas Gerais, introdução de Francisco Iglesias, Belo Horizonte, Fundação João Pinheiro, 1994, p. 120-127, passim. 
do "Fundamento Histórico" quanto do poema "Vila Rica" estavam longe de se limitar à obra de Teixeira Coelho: é o caso também da Geografia histórica da Capitania de Minas Gerais, de autoria do desembargador José Joaquim da Rocha, escrito por volta de 1778 e 1780, e da Breve descrição física, geográfica e política da Capitania de Minas Gerais, escrita por Diogo Pereira Ribeiro de Vasconcelos em 1808. Conclui Lage de Resende que o "Fundamento Histórico" de Cláudio Manuel da Costa foi, com alterações e corrigendas, a matriz histórica de obras como a de José Joaquim da Rocha e depois a de Diogo Pereira Ribeiro de Vasconcelos. Segundo ela, a memorialística setecentista dos descobrimentos do ouro, na qual a narrativa da Guerra dos Emboabas ocupa um lugar central, teria se originado no relato apógrafo de Bento Fernandes Furtado - a fonte narrativa de Cláudio Manuel da Costa - e depois se deslocado para José Joaquim da Rocha, Teixeira Coelho e finalmente para Diogo Pereira Ribeiro de Vasconcelos. ${ }^{11}$ De fato, a descrição de José Joaquim da Rocha dos primeiros anos das Minas, particularmente do contexto em que explode o conflito entre paulistas e emboabas, evoca o estado de natureza formulado por Cláudio Manuel da Costa. Repetindo quase literalmente uma passagem deste autor, Rocha observa que "foi Albuquerque o primeiro que susteve com desembaraço as rédeas do governo; que pisou as Minas com luzimento e firmeza do caráter em que o rei o pusera, que promulgou as leis do soberano e fez respeitar neste continente o seu nome". ${ }^{2}$

A larga apropriação da obra de Cláudio pela memorialística mineira do século XVIII explica assim a consolidação da imagem de Albuquerque como herói pacificador das Minas e a sua difusão em escritos tanto de inspiração paulista, quanto de inspiração emboaba. Tal imagem, associada à passagem do universo da barbárie para o estado de sociedade política, acabaria por se impor também nos estudos históricos produzidos nos séculos seguintes. E, à semelhança das narrativas setecentistas, as polarizações ideológicas que dominaram a historiografia sobre a Guerra dos Emboabas não lograram macular a imagem de Albuquerque, mantida e preservada pela grande maioria dos autores como modelo irretocável de funcionário régio.

\footnotetext{
${ }^{11}$ Maria Efigênia Lage de Resende, "A disputa pela história: traços inscritos na memorialística histórica mineira dos finais do setecentismo", Varia Historia, Belo Horizonte, n. 20, mar. 1999, p. 71.

${ }^{12}$ Joaquim José da Rocha, Geografia histórica da Capitania de Minas Gerais: descrição geográfica, topográfica, histórica e política da Capitania de Minas Gerais, estudo crítico de Maria Efigênia Lage de Resende, Belo Horizonte, Fundação João Pinheiro, 1995, p. 89.
} 
Alguns exemplos ilustram bem esta idéia. Affonso de E. Taunay, empenhado na construção do mito do paulista, destacou as suas altas qualidades, apresentando-o como "hábil e prudente governador", o qual prestara "relevantíssimos serviços ao seu monarca e aos povos do Brasil", tendo sido o responsável pela conservação das Minas. Parafraseando uma passagem de uma das cartas escritas pelo próprio Albuquerque, Taunay observou que, depois da empresa de pacificação, "estavam as Minas pacificadas! Conservadas aquelas conquistas. Já sem diferenças entre forasteiros e paulistas". ${ }^{13}$

Numa perspectiva ideológica diametralmente contrária, Isaías Golgher, defensor ardoroso da causa emboaba, dedicou rasgados elogios ao governador, observando que "foi a maior figura de todos os governadores que Portugal enviou às Minas Gerais”. Na opinião de Golgher, o seu maior feito teria sido "conseguir apaziguar os mineiros sacrificando os interesses dos Paulistas, mas salvando os da Coroa, dentro das condições impostas pela fraqueza da Metrópole, sem, contudo, ferir profundamente os interesses do império”. Para o historiador mineiro, a retirada de Viana, longe de ser uma derrota, assinalava o início em que o "período histórico emboaba adquiria seu maior esplendor, saindo do episódico e entrando definitivamente como fator de maior importância nas eclosões das lutas políticas em Minas Gerais, que brilham como faróis, iluminando o passado e indicando o futuro às gerações, pela luta ativa contra a tirania e pelo amor à liberdade”. A administração de Albuquerque, na perspectiva de Golgher, não mais fazia do que dar continuidade ao governo emboaba, uma vez que ambos se pautavam pela defesa dos interesses da Coroa: "na verdade, a não ser o problema de ordem legal, o movimento dos emboabas beneficiava os interesses imperiais tanto sob o ponto de vista financeiro como político". ${ }^{14}$

Aureliano Leite, um dos historiadores mais comprometidos com a versão paulista, a ponto mesmo de consagrar um apaixonado estudo biográfico ao paulista Amador Bueno da Veiga, é o autor de um pequeno livro sobre a trajetória de Albuquerque, repleto de elogios à sua atuação na Guerra dos Emboabas. Segundo Leite, naquele ocasião o governador teria se revelado um "maneiroso político", dotado de "inteligência e diligência ao serviço do seu amado soberano". Forçado a reconhecer que Albuquerque detestava a gente

13 Affonso de E. Taunay, História geral das bandeiras paulistas, São Paulo, Museu Paulista, 1948 , t. IX.

${ }^{14}$ Isaías Golgher, Guerra dos emboabas, a primeira guerra civil nas Américas, Belo Horizonte, Conselho Estadual de Cultura de Minas Gerais, 1982, p. 199-202. 
de São Paulo, Leite chama a atenção, no entanto, para a amabilidade com que tratou os paulistas, o que evidenciaria certo respeito por eles e o receio de tê-los como inimigos. ${ }^{15}$

Nada se compara, porém, à sofisticação analítica de Diogo de Vasconcelos, para quem Albuquerque teria sido "o maior vulto do governo colonial da América". ${ }^{16}$ Descrevendo a chegada de Albuquerque a Lisboa em plena primavera, Vasconcelos extravasa a sua costumeira verve poética: "montes abotoados de ramagens novas e floridas, zéfiros embalsamados de perfumes, o rio azul e cintilante, o sol carinhosamente fecundando a terra, tudo parecia enfim predisposto a receber o herói que voltava da América, legando a Minas a grandeza imperecível de seu nome, e de seu trabalho". Acima de tudo, impressionava Vasconcelos a natureza colossal da missão do governador: "estava, portanto, em mãos de Albuquerque uma enorme massa multicor e heterogênea, de origens diversas, de posições desiguais, fermentada de vícios e ódios, de orgulho e de cóleras, massa, que ele tinha por missão reduzir à figura das leis, e converter em pacífico seminário de gerações futuras! Longo, pois, seria enumerar o trabalho, que assoberbou esse grande homem, fundador de nossas municipalidades, no pouco tempo que esteve nas Minas". ${ }^{17}$

Historiador sério e competente, Vasconcelos não ignorava o fato de que a atuação de Albuquerque não só fora parcial, mas se alinhara explicitamente ao partido emboaba. Nada disso, porém, parecia importar, uma vez que era preciso levar a civilização e a ordem àquele cenário dominado pela tirania e despotismo dos homens mais ricos. Recentemente, Marco Antônio Silveira investigou a matriz republicana que estrutura a obra de Vasconcelos, apontando-o como o autor que "melhor fixou o modelo que concebe a evolução histórica das Minas como a gradual vitória do Estado sobre a natureza inóspita e a irracionalidade de uma vida social turbulenta e pouco complexa - isto é, como a vitória da civilização sobre o estado de natureza". ${ }^{18}$

\footnotetext{
${ }^{15}$ Aureliano Leite, O cabo-maior dos paulistas na guerra com os emboabas, São Paulo, s/n, 1961, p. 98.

${ }^{16}$ Sobre a visão dos governadores na historiografia mineira, ver Laura de Mello e Souza, Norma e conflito: aspectos da história de Minas no século XVIII, Belo Horizonte, Editora da UFMG, 1999, p. 185.

${ }^{17}$ Diogo de Vasconcelos, História antiga das Minas Gerais, Belo Horizonte, Itatiaia, 1974, p. 95, passim.

${ }^{18}$ Marco Antônio Silveira, "Guerra de usurpação, guerra de guerrilhas: conquista e soberania nas Minas setecentistas", Varia Historia, Belo Horizonte, n. 25, jul. 2001, p. 124.
} 
Parece legítimo afirmar que o alto apreço que Albuquerque sempre gozou junto à historiografia se deve principalmente a duas ordens de interpretação histórica: para alguns, ele é o exemplo mais bem acabado do governante eficiente e reto, que teria se destacado pela faculdade de agir de forma equânime numa situação extremamente difícil, sobrepondo-se às divergências locais para fazer valer os interesses da Coroa. Tal virtude, resultante tanto de um caráter louvável quanto de uma sólida experiência na administração colonial, o projetaria para além da galeria de governantes mesquinhos e corruptos que estiveram à frente da capitania de Minas Gerais ao longo do século XVIII. Para outros, Albuquerque teria sido muito mais um herói civilizador do que um herói pacificador, uma vez que teria sido o primeiro a introduzir o poder da Coroa num território dominado pela anarquia, no qual imperavam potentados violentos e despóticos, prestes a perpetrar as maiores atrocidades. E não é à toa que para grande parte dos estudiosos, a história mineira se divide em antes e depois de Albuquerque: do estado de natureza, descrita em tintas hobbesianas, ao estado de sociedade, do qual a Coroa portuguesa, através da figura do governante, teria sido a grande artífice. Vale lembrar que esta interpretação deita raízes mais distantes: se ela aparece no Discurso Histórico Político, de autoria atribuída ao conde de Assumar, não há como negar a influência deste topos nos escritos e documentos produzidos sobre a região mineradora entre fins do século XVII e os primeiros anos do século XVIII, a exemplo da obra de Antonil. No caso de Assumar, é interessante notar que foi ele um dos poucos autores a desmontar o mito de Albuquerque como governante justo: o perdão concedido a todos os revoltosos afigurou-se-lhe como a promessa de impunidade para os moradores das Minas, que se prodigalizaram em motins e revoltas, convencidos de que o castigo não os alcançaria. ${ }^{19}$

Afinal, seria Albuquerque de fato um verdadeiro herói pacificador, o responsável pela introdução da ordem em meio à anarquia em que viviam as populações das Minas? Sua ação política encaixar-se-ia no perfil de governante virtuoso e justo que se construiu na historiografia? Ou ainda, teria sido ele escolhido a dedo para apaziguar o conflito entre paulistas e emboabas, como querem os historiadores? Esta última questão remete para um dos deslocamentos mais significativos que resultou da heroicização de Albuquerque: ao contrário do que afirma a grande maioria dos estudiosos, sua nomeação ocorreu quando

${ }_{19}$ Discurso histórico e político sobre a sublevação que nas Minas houve no ano de 1720, estudo crítico, estabelecimento do texto e notas de Laura de Mello e Souza, Belo Horizonte, Fundação João Pinheiro, 1994, p. 154. 
não se tinha notícia ainda na Corte das dissensões entre paulistas e forasteiros. É certo que desde algum tempo vinha se cogitando entre os ministros régios sobre a criação de um governo político nas Minas, chegando-se à conclusão de que se devia escolher "uma pessoa de muita autoridade, ilustre pelo sangue, grande pela dignidade, e maior pelas virtudes, em quem concorra valor, prudência, sofrimento, dissimulação e um sumo desinteresse". ${ }^{20}$ Inegavelmente, a escolha do nome de Albuquerque se relacionava sobretudo com o cenário de instabilidade política da região mineradora e ao temor de uma guerra civil, cuja eclosão os conselheiros régios vaticinavam havia algum tempo, impressionados com as notícias aterradoras que chegavam à Corte. Como mostram os estudos de Nuno Gonçalo Monteiro e Mafalda Soares da Cunha, um dos critérios importantes na escolha dos governantes era precisamente o estado de necessidade do território em causa, o que bem se aplicava à nova conjuntura política das Minas. ${ }^{21}$ A nomeação de Albuquerque aconteceu em fins de 1708 e sua chegada ao Rio de Janeiro só ocorreu em julho de 1709, quando não se sabia ainda em Lisboa sobre os acontecimentos em Minas. ${ }^{22}$ Aliás, as notícias sobre o levante só chegariam aí por volta de agosto - atraso que o Conselho Ultramarino atribuirá à negligência do governador D. Fernando Martins de Lencastre, acusado de ter omitido do rei o que se passava nas Minas.

Aos cinquenta e três anos, D. Antônio de Albuquerque figurava entre os mais experientes e importantes funcionários dos quadros régios, saído de uma família cujo nome se ligava indissociavelmente à administração portuguesa no ultramar. ${ }^{23}$ Sua família aparentava-se diretamente com os Albuquerques Coelhos de Pernambuco, radicados em Pernambuco desde o século XVI, onde

20 "Sobre os papéis que se ofereceram de arbítrios acerca das minas para com eles se segurarem os interesses da Fazenda Real e se pôr em melhor forma o governo daquelas terras". Lisboa, 17 jul. 1709, Documentos Históricos, v. 93, p. 219-242.

${ }^{21}$ Mafalda Soares da Cunha, "Governo e governantes do Império português do Atlântico (século XVII)". In: Maria Fernanda Bicalho \& Vera Lúcia Ferlini (org.), Modos de governar: idéias e práticas políticas no Império português. Séculos XVI a XVIII, São Paulo, Alameda, 2005, p. 73.

${ }^{22}$ Arquivo Histórico Ultramarino, Rio de Janeiro, Códice 232, "Sobre a carta que escreveu Domingos Duarte do Rio de Janeiro a esta corte a Manoel Mendes Pereira, e o capítulo de outra carta para outra pessoa, nas quais se trata das diferenças que se acham nos paulistas com os reinóis deste Reino", fl. 266. A deduzir pelo parecer do Conselho Ultramarino, as cartas escritas por D. Fernando ao rei em fevereiro daquele mesmo ano não haviam ainda chegado a Lisboa (chegariam uma semana depois), sendo que as cartas dos particulares, escritas curiosamente entre os meses de janeiro e fevereiro, é que haviam trazido a notícia do levantamento.

${ }^{23}$ Laura de Mello e Souza, Norma e conflito: aspectos da história de Minas no século XVIII, Belo Horizonte, Editora da UFMG, 1999, p. 184. 
eram grandes proprietários rurais ou exerciam cargos públicos ou funções militares. ${ }^{24}$ As ligações familiares com o Nordeste brasileiro levariam alguns a imputar certo espírito nativista a ações de Albuquerque no contexto do levante emboaba, supostamente identificado com a causa local. Nada mais errôneo, como se verá adiante.

Filho do antigo capitão-mor do Maranhão, de mesmo nome, Albuquerque fizera uma carreira em que se destacavam os feitos militares: governador do Maranhão, Grão-Pará e Rio Negro, ao longo de mais de vinte e cinco anos, esteve à frente da expulsão dos franceses das Guianas, e das lutas contra os índios aruaques. Em fins de 1699, quando se encontrava à frente do governo do Maranhão, uma grave doença fê-lo pedir demissão. ${ }^{25} \mathrm{Um}$ ano depois, em razão do silêncio da Coroa, pedia novamente demissão, solicitando que fosse fretado um navio para que pudesse retornar a Lisboa, retornando finalmente em 1701. ${ }^{26}$ De volta ao Reino, em 1701, depois de convalescer da grave doença contraída no Maranhão, engajou-se na Guerra da Sucessão de Espanha, onde ocupou o importante cargo de governador da Praça de Olivença.

A nomeação para o cargo de governador-geral da capitania do Rio de Janeiro coincidiu com um novo reordenamento estratégico da zona mineradora na geopolítica do Império português. A larga experiência de Albuquerque nos negócios coloniais fazia dele a pessoa mais apta a enfrentar as dificuldades advindas da implantação de governo político numa região dominada pelos poderosos e potentados locais, onde os seus conhecimentos militares certamente seriam decisivos. E foi com esta disposição enérgica e firme que ele tomou para si a missão de subir às Minas e pacificar os revoltosos: mal desembarcado no Rio de Janeiro, tratou logo de aviar uma expedição para lá, convencido de que era mais prudente viajar disfarçado, em vestes simples e modestas, sem o luzimento do aparato do cargo que ocupava.

Pouco se sabe sobre a entrada de Albuquerque nas Minas - e o que se sabe provém da narrativa de sua autoria, escrita diretamente ao rei, com o

${ }^{24}$ Evaldo Cabral de Mello, A fronda dos mazombos: nobres contra mascates, Pernambuco, $1666-$ 1715, São Paulo, Editora 34, 2003, p. 314.

${ }^{25}$ Arquivo Histórico Ultramarino, Maranhão, caixa 9, doc. 984, Consulta do Conselho Ultramarino ao rei D. Pedro II, sobre o pedido de demissão formulado pelo governador do Maranhão, Antônio de Albuquerque Coelho de Carvalho, por motivo de doença, que também solicita nomeação de seu sucessor. Lisboa, 14 out. 1699.

${ }^{26}$ Arquivo Histórico Ultramarino, Maranhão, caixa 10, doc. 1.020, Requerimento do governador e capitão-general do Maranhão, Antônio de Albuquerque Coelho de Carvalho, ao rei D. Pedro II, em que solicita que lhe seja fretado um navio para regressar ao Reino, em virtude da sua doença. Lisboa, 23 out. 1700 
propósito de dar conta do estado dos sertões mineiros. A correspondência das autoridades locais, sobretudo os governadores, carece ainda de análises mais refinadas, atentas para a natureza enganosa de uma fonte destinada, antes de tudo, a impressionar ao rei e seus ministros. Dispositivo de manipulação calculada, as cartas escritas por Albuquerque sobre o seu tour pelo olho do furacão surpreendem pelo tom plácido e sereno: em vez de esbarrar na resistência encontrada por seu antecessor, Albuquerque encontrou paulistas e emboabas dispostos a aceitar humildemente todas as formas de acordo propostas por ele. Menos que um quadro veraz do cenário mineiro, o que tais cartas buscam, ao omitir as dificuldades e amenizar os obstáculos, é sobretudo construir a imagem da "quietação e sossego", apropriada ao desempenho de um bom administrador do Império ultramarino.

Se as disposições dos ministros régios tendiam para o estabelecimento de um equilíbrio entre os revoltosos, como o resultado de um intrincado processo de negociação, em que os interesses de ambas as partes pudessem encontrar acolhida, não era bem este o plano de Albuquerque, homem suficientemente experimentado no mundo colonial para perceber a intensidade dos ódios que separavam paulistas e emboabas. Ademais, o próprio governador estava irremediavelmente convencido de que os paulistas deveriam ser expulsos da região, pois era gente abominável, incapaz de participar do governo político que a Coroa pretendia implantar ali.

Não cabe aqui examinar detalhadamente o plano de pacificação concebido por Albuquerque para resolver aquela que era, sem dúvida, uma das ameaças mais graves sofridas pela Coroa na vasta extensão de seu império. O que importa destacar é a evidência irrefutável de que, fosse por motivos políticos, estratégicos ou mesmo pessoais, seu propósito foi antes legitimar o domínio emboaba do que estabelecer um diálogo entre as partes em conflito. Dito de outro modo, Albuquerque nada mais fez do que cooptar o governo emboaba, colocando os seus homens sob o manto do rei, e ao fazê-lo rechaçou definitivamente os paulistas da cena mineira. Isto fica claro quando se examina as cartas escritas por ele ao rei, entre fins de 1709 e início de 1710, onde relata as providências administrativas que a situação o obrigara a tomar. Aliás, é curioso observar como as entrelinhas de sua narrativa se chocam com o tom geral da carta, supostamente movida pelo desejo de negociação e pacificação. Ainda em agosto, quando pisou nas Minas, explica ao rei o critério adotado para o estabelecimento da estrutura administrativa na região, aludindo tão-somente 
ao processo de destituição e à confirmação dos cargos militares, sem contudo mencionar novas nomeações. Em suas palavras: "só faço conta conservar os capitães das ordenanças, pois sempre estes foram por votos do povo, e determino regular estas de sorte que fiquem em defesa prontos e por lhe seu capitão-mor em cada distrito e minas tem custado pouco este negócio em que tenho ainda muito que trabalhar pelo amor que criaram aos bastões". ${ }^{27}$

É bem pouco provável que Albuquerque tivesse apenas cuidado da confirmação dos postos militares, deixando de lado aspectos essenciais da administração local, como a arrecadação dos quintos e a distribuição de datas minerais, dos quais dependia o bom andamento dos trabalhos de mineração. Obviamente, a mera deposição dos oficiais nomeados pelo governo emboaba não só levaria os negócios ao caos, mas também contrariava os interesses da Coroa, para quem o mais importante era precisamente garantir os rendimentos para a Fazenda Real. Examinando mais detidamente a atuação de Albuquerque, fica evidente que o seu plano de pacificação limitava-se a afastar as lideranças mais destacadas, sobretudo Manuel Nunes Viana - já bastante enfraquecido pelas dissensões internas -, substituindo-as por nomes ligados ao partido emboaba, desde que estivessem dispostos a prestar-lhe subordinação. $\mathrm{O}$ restante da estrutura administrativa seria mantido na sua quase totalidade. Tratava-se de um plano bastante astucioso, pois que não abalaria radicalmente o governo emboaba, garantindo-lhe a continuidade mesmo sem a presença de seu principal líder. Um malogro só teria lugar se Nunes Viana, apoiado por seus seguidores, lhe fizesse resistência aberta, ou, na hipótese mais verossímil, se os paulistas colocassem tudo a perder, contestando a manutenção dos provimentos dos emboabas - o que viria a suceder muito antes do que Albuquerque pudesse imaginar.

Um olhar mais detido sobre as cartas escritas entre agosto e outubro de 1709 põe em evidência um aspecto intrigante: o que elas dão a ver é a ausência perturbadora dos paulistas. Eles são sequer citados na narrativa da suposta pacificação. E não é difícil explicar o motivo dessa omissão. Quase um ano depois, Albuquerque, reportando-se às providências que tomara, notou que os

\footnotetext{
${ }^{27}$ Arquivo Histórico Ultramarino, Rio de Janeiro, caixa 8, doc. 867. Consulta do Conselho Ultramarino ao rei D. João V sobre cartas do governador interino do Rio de Janeiro, o mestre-de-campo Gregório de Castro de Moraes, acerca da tranquilidade em que se encontra a mesma capitania e o cumprimento das ordens passadas ao governador [do Rio de Janeiro, nomeado para São Paulo e Minas] Antônio de Albuquerque Coelho de Carvalho [para ir à região das minas]. Lisboa, 29 jan. 1710. Carta de Antônio de Albuquerque ao rei. Povoação do Caethé, 17 ago. 1709.
} 
paulistas, "como são de natural tímidos, e foram causadores do levantamento, não deixam de andar como corridos e humildes". ${ }^{28}$ Alguns meses antes, o bispo do Rio de Janeiro também observara que as Minas estavam sossegadas, porque "como destes [os paulistas] os mais destemidos e culpados se ausentaram para as suas pátrias, cessaram estas discórdias e ficou o corpo das Minas pacífico como está". Curiosamente, juntava o bispo que "só com as minas estão opostos e discordes os paulistas que vivem em São Paulo e vilas circunvizinhas". ${ }^{29}$

Foi sobretudo a ausência dos paulistas, embrenhados pelos matos ou de volta às vilas vicentinas, o que proporcionou a Albuquerque as condições necessárias para a cooptação do partido emboaba, sob a forma de confirmação de postos, cargos e patentes. Menos que afastá-lo do poder, tratava-se de trazê-lo para a órbita da Coroa, sujeitando-o ao poder régio. E não é à toa que, anos mais tarde, escrevendo sobre o levante emboaba, o conde de Assumar o chamaria de "o primeiro e mais escandaloso motim que nas Minas houve", lastimando o fato de que não só o líder emboaba não fora punido, mas antes glorificado: "e quando se espera que, a indignações da Majestade, chovessem por toda a parte raios, e que a tanto atrevimento fossem leve campa todos os montes das Minas, foi Manuel Nunes tão ditoso (se é que pode haver dita entre a maldade) que o seu delito lhe redundou em glória, sendo na Bahia bem recebido dos mesmos a quem tocava e deviam punir severamente o delito; e nestas Minas apareceu como arco de bonança, segurando a todos da tempestade que se temia o Santelmo do perdão, em que os confirmou verem-se todos conservados nos mesmos postos que Manuel Nunes criara, com o que lhes ficou a mão tão folgada, e ele tão insolente e desvanecido..." ${ }^{30}$

Pouco depois, escrevendo sobre o episódio, Rocha Pita notaria que a missão de Albuquerque se resumira tão-somente a endossar as nomeações feitas pelo governo emboaba, confirmando "os postos, que Manuel Nunes Viana, a instância, e por nomeação dos povos havia criado; os mais deles pro-

\footnotetext{
${ }^{28}$ Arquivo Histórico Ultramarino, Minas Gerais, caixa 1, doc. 28. Carta de Antônio de Albuquerque Coelho Carvalho, governador das Minas Gerais, para D. João V, lembrando que se devem arrematar as rendas do governo e as dos dízimos dos frutos da terra. Minas Gerais, 7 ago. 1711.

${ }^{29}$ Arquivo Histórico Ultramarino, Rio de Janeiro, doc. 896. Consulta do Conselho Ultramarino ao rei D. João V, sobre a ordem que fora dada ao Bispo do Rio de Janeiro, [D. frei Francisco de São Jerônimo], para que passasse às Minas a fim de acalmar as discórdias entre os paulistas e os reinóis, estabelecer paróquias para administrar os sacramentos entre os moradores daquela região e expulsar os religiosos e clérigos ali residentes. Carta do bispo ao rei. Rio de Janeiro, 13 mar. 1710.

${ }^{30}$ Discurso histórico e político sobre a sublevação que nas Minas houve no ano de 1720, p. 154.
} 
veu nas próprias pessoas, que os estavam exercendo, por entender, que eram capazes de os ocupar; fez outros de novo, ordenando todas as suas disposições ao maior serviço d'El-Rei, e sossego de todos, com tão geral satisfação, quanto eram uniformemente bem recebidas as suas resoluções, que reconheciam por acertadas". ${ }^{31}$

Semelhante versão atravessaria séculos, despontando por fim na obra de Diogo de Vasconcelos: "como em verdade Manuel Nunes no provimento dos ofícios e postos, que fez escolheu sempre o melhor pessoal dos lugares, não quis Albuquerque destituí-lo mas para não ceder de sua autoridade, mandou passar aos serventuários novas provisões e patentes". Ainda segundo Vasconcelos, Borba Gato fora mantido no cargo de superintendente do Rio das Velhas, enquanto que, no Caeté, confirmara-se a nomeação de Sebastião Pereira de Aguilar, e no Rio das Mortes, a do capitão-mor Pedro de Morais Raposo. ${ }^{32}$ Mais recentemente, Maria Verônica Campos observou que: "a estratégia de Antônio de Albuquerque fora eficaz. Tratou diretamente com o líder dos emboabas e evitou o desgaste maior de negociações e conflitos. Minada a liderança, ficariam os demais obedientes. Adicionalmente, manteve alguns dos postos militares e cargos da administração civil nas mãos dos revoltosos e processou a substituição de outros por paulistas e cariocas". ${ }^{33}$

Se à versão emboaba convinha associar a pacificação à vitória dos seguidores de Manuel Nunes Viana, projetando sobre a figura de Albuquerque as virtudes do bom governante, não era este o caso da versão paulista, cujos gérmens se encontram em Cláudio Manuel da Costa, o primeiro historiador do episódio a partir da perspectiva dos vencidos - cuja derrota, porém, é simplesmente ignorada. O desafio imposto a ele e seus sucessores pode ser assim resumido: se Albuquerque constituía o arauto da ordem e da civilização, como então expor a antipatia que o separava dos paulistas sem incorrer na velha imagem de homens bárbaros e rudes?

A imagem de herói pacificador, consagrada sobretudo por Cláudio Manuel da Costa no poema "Vila Rica" e dominante na historiografia, tendeu a eclipsar a forma pouco equânime com que Albuquerque distribuiu cargos e postos no novo governo. Afinal, a "composição entre emboabas e paulistas",

\footnotetext{
${ }^{31}$ Pita, op. cit., p. 245-246.

${ }^{32}$ Vasconcelos, op. cit., p. 80-81.

${ }^{33}$ Maria Verônica Campos, Governo de mineiros: 'de como meter as minas numa moenda e beberlhes o caldo dourado' (1693 a 1737), tese de doutorado apresentada à F.F.L.C.H. da Universidade de São Paulo, 2002, p. 95.
} 
recomendada pelo Conselho Ultramarino, era uma ordem praticamente impossível de ser cumprida e ele preferiu calar-se a este respeito, poupando a Coroa de detalhes excessivos sobre a intensidade do ódio que separava ambos os partidos. O certo é que a sua atuação não conseguiu reverter a debandada dos paulistas, iniciada por ocasião da aclamação de Nunes Viana e continuada mesmo depois de sua chegada à região. E tampouco era esse o seu objetivo.

Não é difícil entender as razões que levaram Albuquerque a referendar as nomeações feitas anteriormente por Nunes Viana. Tratava-se de uma questão estratégica vital, da qual dependia o êxito de sua missão: a deposição de todo o governo emboaba certamente lhe custaria a incômoda suspeita de inclinação aos paulistas, pondo a perder o seu plano de pacificação. Qualquer acordo negociado naquelas circunstâncias, quando as hostilidades ainda estavam muito frescas na memória e os ódios recíprocos exacerbados, estaria fadado a ser unilateral. E, obrigado a escolher entre paulistas e emboabas, Albuquerque não hesitou em escolher os últimos. Afinal, ele deixara evidente, desde a chegada às Minas, a sua reiterada antipatia pelos homens do Planalto, expressa na correspondência trocada com o Conselho Ultramarino, acolhendo in totum a versão emboaba e atribuindo-lhes toda a culpa pelo levantamento. Sobre esses homens, escreveu em tom cáustico: "no que toca aos paulistas, vou dispondo os ânimos para que os aceitem quando se sujeitem a viver como eles [emboabas] obedientes às justiças e governo que pedem para estas Minas, do que na verdade necessitam muito e com a maior brevidade, assim pela dilatado?, como pela liberdade com que se criaram". ${ }^{34}$

Ao contrário de seu antecessor, que cuidara de reunir os procuradores de ambos os partidos para promover a paz, Albuquerque ignorou por completo o fato de que grande parte dos paulistas que haviam sido espaventados pelos forasteiros permanecia ainda fora da região. Soa também desconcertante a sua afirmação, feita em setembro de 1709, de que as Minas estavam finalmente pacificadas e os povos sossegados, quando já se sabia que os paulistas esta-

\footnotetext{
${ }^{34}$ Arquivo Histórico Ultramarino, Rio de Janeiro, caixa 8, doc. 867. Consulta do Conselho Ultramarino ao rei D. João V sobre cartas do governador interino do Rio de Janeiro, o mestre-de-campo Gregório de Castro de Moraes, acerca da tranquilidade em que se encontra a mesma capitania e o cumprimento das ordens passadas ao governador [do Rio de Janeiro, nomeado para São Paulo e Minas] Antônio de Albuquerque Coelho de Carvalho [para ir à região das minas]. Lisboa, 29 jan. 1710.
} 
vam preparando um grande ataque. ${ }^{35}$ Tanto é assim que ele próprio tratou de despachar o padre Simão de Oliveira à vila de São Paulo para demovê-los daquele propósito. ${ }^{36}$ Tratava-se, em suma, de um acordo bilateral, do qual os paulistas estavam excluídos, o que, inegavelmente, facilitou em muito a tarefa de Albuquerque.

Antipático à causa paulista, Albuquerque também reprovou a concessão do indulto geral aos revoltosos, preferindo que se aplicasse um castigo exemplar aos paulistas, alegando não serem "merecedores de nenhuma compaixão ou benignidade, pela com que usei com eles, quando os encontrei, do que abusaram tão mal, como se experimentou no Rio das Mortes". ${ }^{37}$

Se a concessão de indulto a paulistas e emboabas decorria da política de prudência com que a Coroa tratava os seus vassalos ultramarinos, associando-a à imagem de magnanimidade e benevolência do rei, ela também deve ser vista na perspectiva das particularidades da zona mineradora. Afinal, quais eram as chances efetivas de uma repressão bem sucedida a forasteiros e paulistas, num contexto de ameaça de uma invasão estrangeira, tendo-se em vista a distância da Praça da Bahia, a única que poderia fornecer tropas de soldados para fazer frente ao movimento? Praticamente nulas. Do ponto de vista das operações militares, a repressão esbarraria no alto contingente militar e na cuidadosa organização tática dos forasteiros, responsáveis pela fragorosa derrota dos paulistas. O próprio Albuquerque chegara a conjecturar sobre a possibilidade de uma investida militar ao Planalto, à primeira vista mais acessível que os sertões mineiros, lembrando que ela só seria bem sucedida em razão de as vilas se encontrarem enfraquecidas: "a ocasião me parecia fácil com a atenuação

\footnotetext{
${ }^{35}$ Arquivo Histórico Ultramarino, Minas Gerais, caixa 1, doc. 22. Carta de Antônio de Albuquerque Coelho de Carvalho, autoridade pacificadora da Guerra dos Emboabas, a D. João V, dando conta das suas ações na pacificação da região mineradora e da resistência dos paulistas às suas determinações. s/d.

${ }^{36}$ Arquivo Histórico Ultramarino, Rio de Janeiro, caixa 8, doc. 867. Consulta do Conselho Ultramarino ao rei D. João $\mathrm{V}$ sobre cartas do governador interino do Rio de Janeiro, o mestre-de-campo Gregório de Castro de Moraes, acerca da tranquilidade em que se encontra a mesma capitania e o cumprimento das ordens passadas ao governador [do Rio de Janeiro, nomeado para São Paulo e Minas] Antônio de Albuquerque Coelho de Carvalho [para ir à região das minas]. Lisboa, 29 jan.1710. Carta de Antônio de Albuquerque ao rei. Povoação do Caethé, 17 ago. 1709.

${ }^{37}$ Carta de Antônio de Albuquerque Coelho de Carvalho a D. João V sobre a Guerra dos Emboabas. Rio de Janeiro, 3 abr. 1710. Documentos Interessantes para a história e costumes de São Paulo, v. 47, p. 73.
} 
em que se acham". ${ }^{38}$ Do mesmo modo, ele julgava as vilas vicentinas "fáceis de conquistar, por estarem mui atenuadas". ${ }^{39}$ Muito diferente, contudo, seria uma operação militar em plena zona mineradora, praticamente inacessível às tropas saídas do Rio de Janeiro. A questão geográfica - comumente desprezada pela historiografia - deve ser considerada como um dos fatores decisivos na natureza das relações da Coroa com os vassalos mineiros: muito frequentemente as condições efetivas de uma repressão militar pesaram mais do que as formulações políticas sobre a necessidade da magnanimidade régia.

Afora as dificuldades ecológicas e estratégicas, o momento tampouco era oportuno para as grandes demonstrações de força, tendo-se em vista o projeto da Coroa de estabelecer o governo político e militar na região, submetendo-a à órbita do Império. Nesse caso, a prudência seria um lance mais do que estratégico. Além disso, uma ofensiva militar corria também o risco, em última instância, de aglutinar os adversários em torno de uma causa comum - o repúdio à Coroa -, unindo forças que dificilmente seriam vencidas pela máquina de guerra portuguesa, às voltas, por sua vez, com a sombra ameaçadora de uma invasão estrangeira no litoral.

Outra evidência inequívoca da disposição de Albuquerque em espaventar os paulistas da estrutura administrativa da região é o fato de que, tendo recebido ordens para promover a "união entre os moradores de São Paulo e mais distritos das mesmas Minas", ${ }^{40}$ preferiu ignorá-las, para favorecer acintosamente os interesses dos emboabas, beneficiados na distribuição de sesmarias, datas minerais, cargos civis e militares. ${ }^{41}$ No caso das sesmarias, o descontentamento dos paulistas ficou registrado numa representação enviada pela Câmara de São Paulo, em setembro de 1710, à Coroa, pedindo a restituição

${ }^{38}$ Carta de Antônio de Albuquerque Coelho de Carvalho a D. João V sobre a Guerra dos Emboabas. Rio de Janeiro, 3 abr. 1710. Documentos Interessantes para a história e costumes de São Paulo, v. 47, p. 73.

${ }^{39}$ Arquivo Histórico Ultramarino, Minas Gerais, caixa 1, doc. 22. Carta de Antônio de Albuquerque Coelho de Carvalho, autoridade pacificadora da Guerra dos Emboabas, a D. João V, dando conta das suas ações na pacificação da região mineradora e da resistência dos paulistas às suas determinações. $\mathrm{s} / \mathrm{d}$.

${ }^{40}$ Carta patente a Antônio de Albuquerque. Lisboa, 23 nov. 1709. Citado por Afonso de E. Taunay, "História da vila de São Paulo", Anais do Museu Paulista, São Paulo, Imprensa Nacional, 1931, tomo quinto, p. 79-155, p. 151.

${ }^{41}$ Segundo Maria Verônica Campos, "constatadas as dificuldades para a imposição de um método eficaz de cobrança do quinto, Antônio de Albuquerque tratou de cumprir as ordens sobre a distribuição do poder entre paulistas e forasteiros, numa combinação de importantes medidas: distribuição de sesmarias; provimento de cargos civis e militares; criação de vilas, instituições e órgãos de governo; e manteve nas mãos dos forasteiros as lavras e propriedades expropriadas durante a Guerra dos Emboabas”. Governo de mineiros, p. 113-114. 
das terras tomadas pelos forasteiros. Alegavam os camaristas que "estando os paulistas senhores de várias terras no sertão das minas pelas haverem povoado e cultivado para suas lavouras, na sublevação que houvera entre os reinóis e os paulistas foram estes expulsos de tais terras, e se assenhorearam delas os forasteiros e as pediram de sesmaria, logrando o trabalho que os paulistas tinham feito nelas sem mais títulos que o de povoadores em cuja fé as logravam, e hoje se achavam destituídos de todo remédio".

Acusavam Albuquerque de ter inadvertidamente concedido aos forasteiros terras de sesmarias que pertenciam aos paulistas. ${ }^{42}$ Consultado sobre a matéria, Albuquerque negou, num primeiro momento, que tivesse feito tal coisa, observando que tudo fizera para conservar os paulistas na posse de suas terras. Num segundo momento, no entanto, ele revelou que "como estes [os paulistas] por natural, e talvez por corridos ainda alguns do que lhes sucedeu no levantamento, desejam viver sós e mais distantes dos forasteiros e da sua vizinhança, não se ocupam muito em pedirem as terras em que lavravam e se acham no distrito das vilas". Tal atitude pareceu-lhe muito conveniente, "por ser mais útil para os descobrimentos que os ditos paulistas se aquartelam mais para os sertões em distância porém das vilas". ${ }^{43}$ Ora, não foram poucas as vezes em que, depois de empossado no governo da capitania de São Paulo e Minas do Ouro, Albuquerque reconhecia, ainda que veladamente, que os paulistas espaventados pelos forasteiros jamais retornaram às Minas, e os que o fizeram permaneceram distantes das vilas e arraiais. Nesse contexto, não é difícil entender por que os paulistas, empurrados para os matos e sertões, foram preteridos na distribuição de sesmarias.

O mesmo ocorreu no processo de provimento de cargos civis e militares, a forma por excelência de distribuição de poder na região. Reportando-se às providências tomadas logo nos primeiros meses da governação, Albuquerque confessaria ao rei que tentara cooptar os paulistas, "animando-os com algumas ocupações e postos, sem exceção de forasteiros, de sorte, que nem estes os invejem, nem seja comum para todos o que não tiverem préstimo”. Mas não

${ }^{42}$ Carta de Antônio de Albuquerque Coelho de Carvalho a D. João V sobre o requerimento da Câmara de São Paulo para que fossem restituídas aos paulistas as terras das minas de que haviam sido expulsos pelos emboabas. Rio de Janeiro, 26 abr. 1712. Documentos interessantes para a história e costumes de São Paulo, v. 47, p. 80.

${ }^{43}$ Carta de Antônio de Albuquerque Coelho de Carvalho a D. João V sobre o requerimento da Câmara de São Paulo para que fossem restituídas aos paulistas as terras das minas de que haviam sido expulsos pelos emboabas. Rio de Janeiro, 26 abr. 1712. Documentos interessantes para a história e costumes de São Paulo, v. 47, p. 80-82. 
obtivera êxito porque todos haviam partido, deixando as Minas nas mãos dos emboabas. Um relato de inspiração pró-emboaba confirma essa versão: segundo o autor, anônimo, a ordem de Albuquerque no sentido de que as câmaras contassem com igual número de reinóis e paulistas, "não durou muitos anos que, como os paulistas eram poucos os que ficaram, e ainda estes estranhavam a vizinhança daqueles, em que achavam diferentes costumes e desconfiavam que se rissem dos seus, foram desertando..." ${ }^{4}$

Sagaz, Albuquerque sabia que a paz naqueles termos era frágil e não resistiria por muito tempo. Logo depois, em 1711, Pitangui explodiria numa série infindável de motins, transformando-se no último bastião paulista encravado em terras mineiras. Ora, todos estes motins, geralmente ignorados pela historiografia, punham em evidência não só a fragilidade da suposta pacificação de Albuquerque mas também a firme disposição dos potentados e régulos que ali se haviam constituído nos anos anteriores, em fazer resistência tenaz - por vezes insidiosa, por vezes aberta - à tentativa da Coroa em implantar sua autoridade na zona mineradora. Nas décadas seguintes, estes homens, investidos de poder absoluto, manteriam sob o seu domínio largas parcelas do território mineiro, nas quais os funcionários nomeados pelo rei mal conseguiam pisar. Os ódios gestados nos primeiros tempos entre paulistas e emboabas jamais seriam aplacados e por todo o lugar ambos os partidos se defrontariam numa luta sem trégua, fazendo reavivar os dias difíceis vividos durante o levante. Em sua breve passagem pela zona mineradora, Albuquerque assistiria às perturbadoras implicações de sua suposta "empresa de pacificação". Se para grande parte da historiografia sua administração limitou-se tão-somente às providências administrativas relativas à criação das vilas, obliterando por completo os inúmeros obstáculos que uma paz tão recente e frágil certamente implicava, o estudo mais recente de Maria Verônica Campos desnuda uma realidade bem diversa: segundo ela, grande é o descompasso entre a imagem de governante eficiente e os resultados concretos alcançados por ele em sua passagem pelo governo da capitania das Minas de Ouro e São Paulo e Minas do Ouro. ${ }^{45}$ Se uma das missões de Albuquerque era cuidar da arrecadação dos tributos, ele simplesmente falhou ao não conseguir impor uma forma eficaz de cobrança. Além disso, durante seu governo explodiram motins encabeçados

44 "Relação de um morador de Mariana e de algumas coisas mais memoráveis sucedidas", Códice Costa Matoso. Belo Horizonte, Fundação João Pinheiro, 1999, coordenação-geral de Luciano Raposo de Almeida Figueiredo e Maria Verônica Campos, p. 207.

${ }^{45}$ Maria Verônica Campos, Governo de mineiros, p. 130. 
pelos potentados constituídos na aurora da história mineira. O fato é que Albuquerque entraria definitivamente para a galeria de grandes heróis da história mineira não tanto em razão dos feitos de sua administração - aliás, pouco estudada - mas sobretudo por sua atuação no apaziguamento da Guerra dos Emboabas, em cuja esteira estava, por exemplo, a criação das primeiras vilas da capitania. Nem tanto a obra de pacificação, ofuscada pela suposta falta de resistência dos revoltosos, quanto o estabelecimento de governo civil numa terra dominada pela anarquia e caos.

Para além das veleidades de Albuquerque, o que de fato pesou na forma com que se conduziu no apaziguamento do levante emboaba foram as ponderações de natureza política. A adesão à causa emboaba se explica sobretudo pela convicção - partilhada pelos funcionários régios - de que os paulistas não eram vassalos leais à Coroa, e que, por essa razão, não podiam ocupar os cargos e posições mais importantes da nova administração. Se não bastasse isso, havia ainda os limites impostos pela conjuntura política: como reprimir um motim em pleno sertão, a uma considerável distância dos centros litorâneos, ameaçados, por sua vez, pela iminência de uma invasão estrangeira?

Vista nesta perspectiva, a obra de pacificação encetada por Albuquerque foi o que poderia ter sido: nem tanto uma pacificação, quanto a aceitação implícita da vitória emboaba, com o consequente afastamento dos paulistas nos negócios da administração da nova capitania. Menos que um herói pacificador, o governador foi antes de tudo um herói emboaba - e, paradoxalmente, a versão paulista, formulada primeiramente por Cláudio Manuel da Costa, endossaria, sem retoques, tal imagem, colocando-a no panteão da história de Minas. Do poema "Vila Rica", a figura de Albuquerque migraria para uma tradição historiográfica influente, transformando-se num dos marcos mais importantes da cronologia histórica do século XVIII mineiro. 